\title{
Buzhongyiqi Decoction Protects Against Loperamide-Induced Constipation by Regulating the Arachidonic Acid Pathway in Rats
}

\section{OPEN ACCESS}

Edited by:

Aiping Lu,

Hong Kong Baptist University,

Hong Kong

Reviewed by:

Yong Wang,

Beijing University of

Chinese Medicine, China

Wentzel Christoffel Gelderblom,

Cape Peninsula University of

Technology, South Africa

${ }^{*}$ Correspondence:

Xiao-Ping Wen

wxpglj@yahoo.com.cn

Guang-Li Du

duguangli2002@126.com

Specialty section:

This article was submitted to

Ethnopharmacology,

a section of the journal

Frontiers in Pharmacology

Received: 04 September 2019

Accepted: 19 March 2020

Published: 03 April 2020

Citation:

Ju W-J, Zhao Z-k, Chen S-L, Zhou D-d, Yang W-N, Wen X-P and Du G-L (2020) Buzhongyiqi Decoction Protects Against Loperamide-Induced Constipation by Regulating the Arachidonic Acid Pathway in Rats.

Front. Pharmacol. 11:423.

doi: 10.3389/fphar.2020.00423

\author{
Wan-Jun Ju ${ }^{1,2}$, Ze-kuo Zhao ${ }^{1}$, Shao-Li Chen ${ }^{1}$, Dan-dan Zhou ${ }^{3}$, Wen-Ning Yang ${ }^{4}$, \\ Xiao-Ping Wen ${ }^{1 *}$ and Guang-Li Du ${ }^{1 *}$
}

${ }^{1}$ Department of Formulaology, School of Basic Medical Sciences, Shanghai University of Traditional Chinese Medicine, Shanghai, China, ${ }^{2}$ Department of Endocrinology, Shanghai Pudong New Area Hospital of Traditional Chinese Medicine, Shanghai, China, ${ }^{3}$ R \& D Department, GenChim Testing Co., Ltd, Shanghai, China, ${ }^{4}$ School of Chinese Materia Medica, Beijing University of Chinese Medicine, Beijing, China

Constipation is a common gastrointestinal disorder without effective treatment approach. Buzhongyiqi decoction (BZYQD) is a classical formula that has been commonly used for gastrointestinal disorders for nearly 1,000 years. In this study, we aimed to investigate the protective effect of BZYQD against loperamide-induced constipation and its potential mechanism. Rats with loperamide-induced constipation were orally administered BZYQD. BZYQD treatment obviously increased the small intestinal transit rate and alleviated colon tissue pathological damage. Subsequently, serum metabolomics study was performed to identify the metabolites affected by BZYQD. Metabolomics identified that the levels of 17 serum metabolites, including prostaglandin $\mathrm{E}_{2}\left(\mathrm{PGE}_{2}\right)$, arachidonic acid (AA), and inositol, were significantly changed in BZYQD-treated group compared with those in the loperamide-induced group. Pathway analysis revealed that those metabolites were mainly associated with arachidonic acid metabolism, biosynthesis of unsaturated fatty acids, ascorbate and aldarate metabolism, inositol phosphate metabolism. Additionally, BZYQD treatment down-regulated the cyclooxygenase-2 expression and decrease production of the proinflammatory mediator $\mathrm{PGE}_{2}$. Further study revealed that BZYQD administration decreased serum levels of the inflammatory factors IL-1 $\beta$ and TNF- $\alpha$, inhibited phosphorylation of the nuclear transcription factor NF- $\mathrm{kB}$, and down-regulated expression of the inflammatory factors $\mathrm{IL}-1 \beta$ and $\mathrm{IL}-6$ in the constipated rat colon. Moreover, BZYQD treatment also increased serum levels of inositol, motilin and gastrin, and promoted gastrointestinal motility. In conclusion, the present study suggested that BZYQD exerted a protective effect against loperamide-induced constipation, which may be associated with its role in regulation of multiple metabolic pathways.

Keywords: constipation, Buzhongyiqi decoction, Metabolomics, Inflammation, rat 


\section{INTRODUCTION}

Constipation is a clinically common gastrointestinal dysfunction with a prevalence of 5-20\% worldwide (Suares and Ford, 2011). According to the Rome IV criteria, a typical symptom of chronic constipation is difficult, infrequent, or inadequate bowel movement (Mearin et al., 2016). Individuals with bowel movement every 3-4 days are at a higher risk of colon cancer, hemorrhoids, and other gastrointestinal diseases (Wu et al., 2010). Laxatives are widely prescribed as the main means to assist patients in passing stools (Li et al., 2019). However, these treatments have severe side effects. Therefore, development of more efficient and safe therapeutic/preventive agents and methods is still needed.

Traditional Chinese medicine (TCM) formulas have been widely used for the prevention and treatment of digestive diseases for thousands of years. Buzhongyiqi decoction (BZYQD) is a well-known TCM formula first described in Pi Wei Lun, a treatise on digestive system diseases written by the famous Chinese physician Li Gao (1180-1251 A.D. of the Chinese Yuan Dynasty) (He et al., 2017). BZYQD is comprised of eight herbs (Table 1) (Ji, 2006) and has been identified as an effective drug for improving the digestive system function, quality of life, and nutritional status in elderly patients with chronic obstructive pulmonary disease (Gou et al., 2016). Moreover, BZYQD is also a representative prescription that is increasingly applied to treat gastrointestinal dysfunction, such as constipation, in China (Wang et al., 1991; Sun Feng-Wei, 2016; Zhang, 2016; Dan, 2018). However, its mechanism of action has not yet been fully investigated.

Metabolomics represents a powerful discipline concerned with the comprehensive analysis of small molecules to discover biomarkers in biological systems (Schrimpe-Rutledge et al., 2016; Zhang et al., 2019). This method provides holistic insights into changes in the metabolic pathways during disease or drug treatment (Wu et al., 2017; Zheng et al., 2019). Therefore, metabolomics study is in perfect accordance with the holistic approach of TCM, and can provide clues to mechanism of action of TCM (Wu et al., 2017; Zheng et al., 2019). In the current study, the effect of BZYQD on loperamide-induced constipation in a rat model was investigated. Additionally, the underlying molecular mechanism of BZYQD in constipation was explored

TABLE 1 | Herbal constituents of BZYQD.

\begin{tabular}{|c|c|c|c|}
\hline Pharmaceutical name & $\begin{array}{l}\text { Chinese } \\
\text { name }\end{array}$ & Part used & $\begin{array}{l}\text { Amount } \\
\text { (g) }\end{array}$ \\
\hline Astragalus mongholicus Bunge & Huangqi & Root & 18 \\
\hline Glycyrrhiza uralensis Fisch. ex DC & Gancao & $\begin{array}{l}\text { Root and } \\
\text { rhizome }\end{array}$ & 9 \\
\hline $\begin{array}{l}\text { Codonopsis pilosula (Franch.) } \\
\text { Nannf. }\end{array}$ & Dangshen & Root & 9 \\
\hline Angelica sinensis (Oliv.) Diels & Danggui & Root & 3 \\
\hline Citrus $\times$ aurantium $\mathrm{L}$. & Chenpi & Pericarp & 6 \\
\hline $\begin{array}{l}\text { Actaea heracleifolia (Kom.) J. } \\
\text { Compton }\end{array}$ & Shenma & Rhizome & 6 \\
\hline Bupleurum chinense DC. & Chaihu & Root & 6 \\
\hline Atractylodes macrocephala Koidz. & Baizhu & Rhizome & 9 \\
\hline
\end{tabular}

by serum metabolomics. Our results provide novel insights into the potential role of the herbal medicine BZYQD in treating gastrointestinal dysfunction diseases.

\section{MATERIALS AND METHODS}

\section{Chemical Compounds and Reagents}

Chromatography-grade acetonitrile was purchased from Merck (Darmstadt, Germany). Water was purified using a Milli-Q water system (Millipore, Bedford, MA, USA). Chromatography-grade acetic acid, formic acid, and methanol were provided by Tedia Company (Fairfield, OH, USA). All the crude drugs including Radix Astragali (Huangqi in China, HQ), Radix Glycyrrhizae (Gancao in China, GC), Rhizoma Atractylodis Macrocephalae (Baizhu in China, BZ), Radix Codonopsis (Dangshen in China, DS), Radix Angelicae Sinensis (Danggui in China, DG), Pericarpium Citri Reticulatae (Chengpi in China, CP), Radix Bupleuri (Caihu in China, $\mathrm{CH}$ ), and Rhizoma Cimicifugae (Shengma in China, SM) were purchased from Shanghai Kangqiao Chinese Medicine Tablet Co., Ltd (Shanghai, China) and authenticated by Gen Chim Testing Co., Ltd (Shanghai, China). Mosapride was purchased from Sigma-Aldrich (St. Louis, MO, USA).

\section{Preparation and Analysis of BZYQD}

BZYQD was prepared according to our previously reported method. A mixture of HQ (18 g), DS (9 g), BZ (9 g), DG (3 g), GC (9 g), CP (6 g), SM (6 g), and CF (6 g) was added to $600 \mathrm{ml}$ water and extracted at $100^{\circ} \mathrm{C}$ for $1 \mathrm{~h}$. The extracted solution was filtered and spray-dried to obtain dry extract powder. The final ratio of BZYQD extract powder to raw herb was $37.80 \%$. The total ion chromatogram of BZYQD extract that measured by LCMS is shown as Figure 1.

\section{Animals and Experimental Design}

Male 8-week-old Sprague-Dawley (SD) rats were provided by the Laboratory Animal Center of Shanghai University of Traditional Chinese Medicine. The animals were housed and acclimatized for one week prior to the experiment in a room at $20-22^{\circ} \mathrm{C}$ and $60-70 \%$ humidity under a $12 \mathrm{~h}$-light and $12 \mathrm{~h}$-dark cycle. All animal experiments were carried out in full compliance with the Guidance of Humane Care and Use of Laboratory and approved by the Committee on the Use of Live Animals for Teaching and Research in the Shanghai University of Traditional Chinese Medicine. Rats were randomly divided into four groups: control (normal control), loperamide, loperamide+BZYQD (1.73 g/kg of BZYQD extract powder), and loperamide +mosapride (positive group, $1.6 \mathrm{mg} / \mathrm{kg}$ ), with 8 rats per group. Rats of the loperamide, loperamide+BZYQD, and loperamide + mosapride groups were treated with loperamide $(4 \mathrm{mg} / \mathrm{kg}, \mathrm{b}$. w.), by subcutaneous injection twice per day at 09:00 and at 18:00 $\mathrm{h}$ for 1 week, and all the corresponding drugs was orally administered to the rats once daily from the third day. Rats in the control group and loperamide group orally received the normal saline. The scheme of the animal experiment is 
A

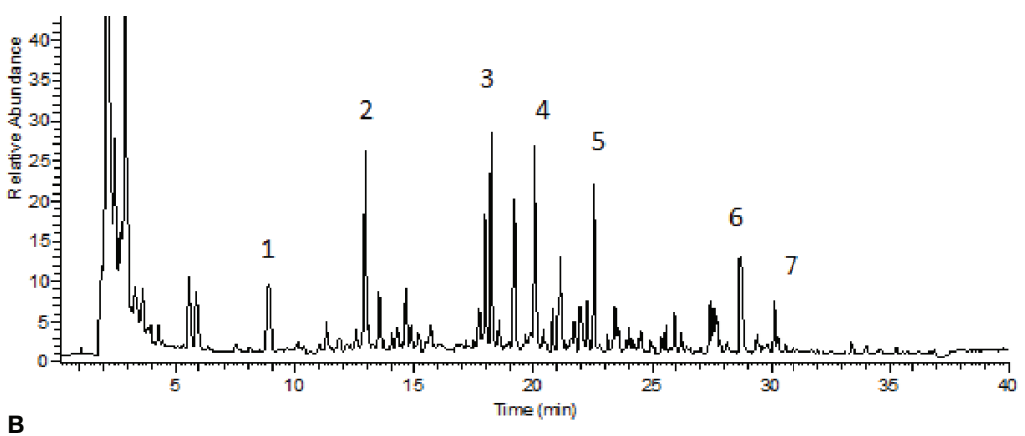

B

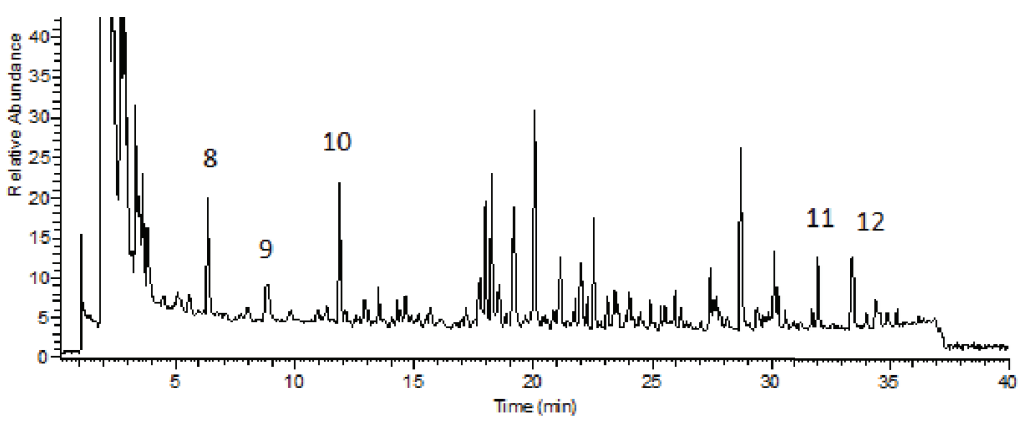

FIGURE 1 | Total ion chromatogram of BZYQD extract in negative-ion mode (A) and positive-ion mode (B). 1: Piscidic acid; 2: Ferulic acid; 3: Liquiritin; 4 Hesperidin; 5: 2-feruloylpiscidic acid; 6: Glycyrrhizic Acid; 7: Saikosaponin D; 8: Synephrine; 9: Codonopyrrolidium B; 10: Tryptophan; 11: Nobiletin; 12: 3, 5, 6, 7, 8, 3', 4'-heptamethoxyflavone.

summarized in Figure 2. A 100\% survival rate was recorded at the end point of the experiment.

\section{Measurement of Gastro-Intestinal Propulsion (GIP)}

All the groups were exposed to fasting conditions and drank only water on the seventh day. GIP was measured through prepared Chinese ink. Thirty minutes later, all animals were fed with the prepared Chinese ink (10\% charcoal in 5\% gum Arabic) and were anesthetized. The small intestine was immediately dissected and put on a clean surface. The travelling distance of the charcoal meal from the pylorus was measured. The gastrointestinal propulsion was calculated based on the following formula: GIP $=($ Distance travelled by charcoal $(\mathrm{cm}) /$ total intestinal length $(\mathrm{cm}) \times 100 \%$. Then, the colon tissues were collected for further studies.

\section{Hematoxylin-Eosin Staining}

Small intestine and colon tissues were fixed in $10 \%$ formaldehyde, dehydrated, embedded in paraffin, cut into $5-\mu \mathrm{m}$-thick sections, and stained with hematoxylin and eosin. Pathological changes were observed using the OlympusBX70 research microscope.

\section{Serum Metabolomics Study Sample Preparation}

An aliquot of $100 \mu \mathrm{l}$ acetonitrile containing the internal standards (IS, $10 \mu \mathrm{g} / \mathrm{ml} \mathrm{2-chloro-L-phenylalanine} \mathrm{in} \mathrm{positive} \mathrm{and} \mathrm{negative}$ modes) was added to $20 \mu \mathrm{l}$ of serum samples. After vortex-mixing for $3 \mathrm{~min}$, the mixture was centrifuged for $10 \mathrm{~min}$ at $16,000 \mathrm{rpm}$ at $4^{\circ} \mathrm{C}$, and $5 \mu \mathrm{l}$ of the supernatant was injected for UPLC-MS/MS analysis. An equal aliquot from each serum sample was combined and mixed to prepare the quality control (QC) samples. The QC samples were processed by the same method as the other serum samples and analyzed randomly through the analytical batch to ensure the stability of the analytical process.

\section{Analysis Conditions}

Sample analysis was performed using a UPLC-LTQ-Orbitrap system (Thermo Fisher Scientific, San Jose, CA, USA) and the samples were separated using a Waters ACQUITY UPLC BEH C18 column $(2.1 \times 100 \mathrm{~mm}, 1.7 \mu \mathrm{m})$ (Waters, Co., Milford, MA, USA). The mobile phases contained water with $0.1 \%$ formic acid (A) and acetonitrile with $0.1 \%$ formic acid (B). The elution steps were as follows: $10 \% \mathrm{~B}$ from $0.1-2 \mathrm{~min}, 10-40 \% \mathrm{~B}$ from $2.1-7$ min, $40-80 \%$ B from $7.1-11 \mathrm{~min}, 80-90 \%$ B from $11.1-15 \mathrm{~min}$, and $90 \% \mathrm{~B}$ for $0.5 \mathrm{~min}$. At $15.5 \mathrm{~min}, \mathrm{~B}$ was adjusted to $10 \%$ and the column equilibrated for $4.5 \mathrm{~min}$. The mass spectrometer parameters were as follows: ion spray voltage, $3.8 \mathrm{kV}(+)$ and 3.2 $\mathrm{kV}(-)$; capillary and heater temperature, both $350^{\circ} \mathrm{C}$; sheath and auxiliary gas flow rate, 45 and 15 psi, respectively; and S-Lens RF level, 60\% (Li et al., 2017; Wu et al., 2017).

\section{Data Processing}

Data preprocessing, identification of potential biomarkers, and pathway analysis were performed as reported previously (Huang 


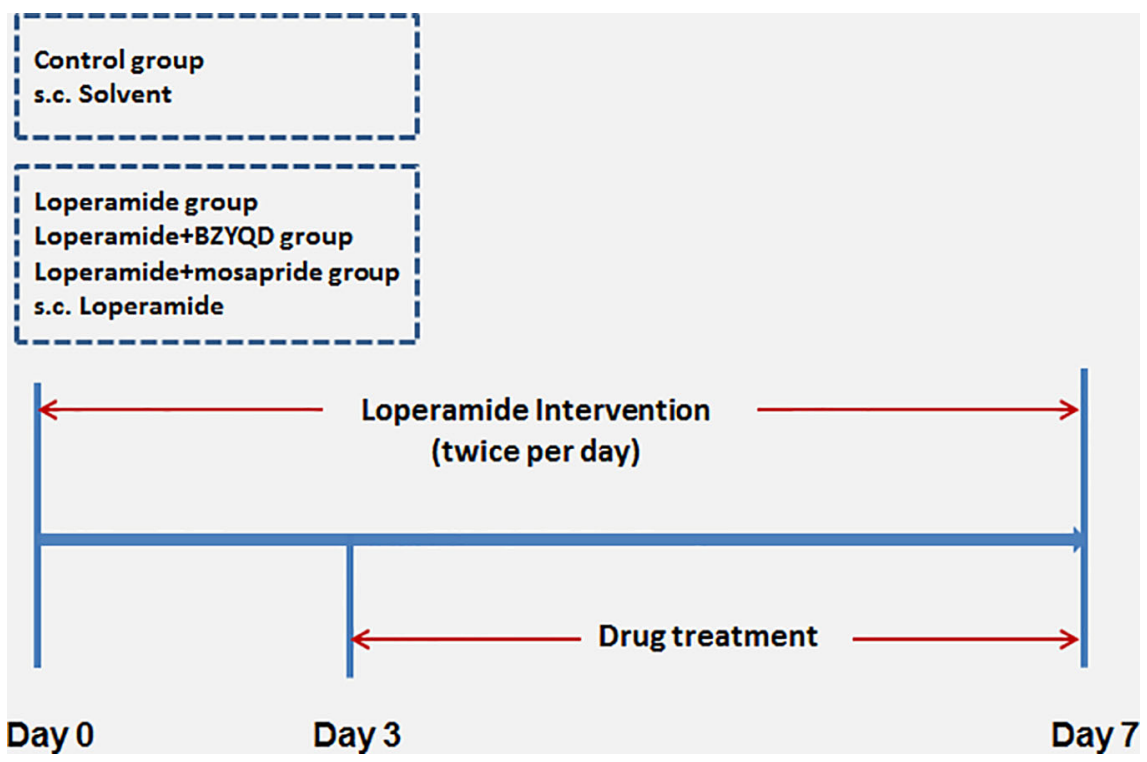

FIGURE 2 | Scheme of experiment. Buzhongyiqi decoction (BZYQD) treatment commenced on day 3, s.c: subcutaneous injection.

et al., 2013; Li et al., 2017). In brief, the raw data of UPLC-LTQOrbitrap were imported to SIEVE to perform peak extraction and matching. Retention time, $\mathrm{m} / \mathrm{z}$ value, and corresponding intensities were recorded. These data were preprocessed as per the rules below: (1) the percentage of valid data in each group must be higher than $80 \%$; (2) the relative standard deviation (RSD) in QC samples must be lower than 30\%; (3) the intensities of each variable should be normalized by the intensity of the IS. After preprocessing, data were imported to SIMCA-P version 14.0 (Umetrics, Sweden) to perform principal components analysis (PCA) and orthogonal partial least squares discriminant analysis (OPLS-DA). The variable importance in projection (VIP) value was calculated in the OPLS-DA model and the Kruskal-Wallis test was conducted. Variables with VIP values more than 1 and $P$ values less than 0.05 were considered potential biomarkers. These potential biomarkers were identified by searching databases such as HMDB (http://www.hmdb.ca/), KEGG (https://www.kegg.jp/), ChemSpider (http://www. chemspider.com/), and mzCloud (https://www.mzcloud.org/), and were finally validated by standard substances to confirm their identity.

\section{Immunohistochemistry Analysis}

Dewaxed, hydrated colon tissue sections were pretreated with antigen retrieval fluid ( $\mathrm{pH}$ 6.0), incubated with $3 \% \mathrm{H}_{2} \mathrm{O}_{2}$ deionized water for $15 \mathrm{~min}$ to block endogenous peroxidase, and rinsed with PBS. IL-6 (1:400) and TNF- $\alpha$ (1:400) were added dropwise and samples incubated overnight at $4^{\circ} \mathrm{C}$. The sections were immersed in PBS, and an IgG antibody and Fab fragmentHRP multimer were added dropwise. The mixture was incubated at $37^{\circ} \mathrm{C}$ for $30 \mathrm{~min}$, and the samples were subsequently washed 5 times with PBS for 3 min each time. Samples were rinsed with distilled water, counter stained with hematoxylin, dehydrated with gradient alcohol, cleared with xylene, and sealed with resin. Positive immunostaining in five random visual fields of the slides was evaluated using an Olympus DP72 optical microscope at a magnification of $\times 200$.

\section{Real-Time Polymerase Chain Reaction (PCR) Analysis}

Total RNA was extracted from colon tissues using Trizol, and cDNA was subsequently synthesized using the Super Script cDNA synthesis kit. Real-time polymerase chain reaction (realtime PCR) was performed using the ABI-StepOnePlus sequence detection system (Applied Biosystems, CA, USA) using the Fast SYBR Green mix kit. The primers used are presented in Table 2. The relative target mRNA expression levels were calculated using the $2^{-\Delta \Delta \mathrm{Ct}}$ method. The expression level of glyceraldehyde 3phosphate dehydrogenase $(G A P D H)$ mRNA was used as the endogenous reference control.

TABLE 2 | Primers of real-time PCR assay used in this study.

\begin{tabular}{|c|c|c|}
\hline GeneName & Specise & Primer sequence $\left(5^{\prime}-3^{\prime}\right)$ \\
\hline \multirow[t]{2}{*}{ Gapdh } & Rat & Forward primer AGGTCGGTGTGAACGGATITG \\
\hline & & Reverse primer GGGGTCGTTGATGGCAACA \\
\hline \multirow[t]{2}{*}{$N F-\kappa B$} & Rat & Forward primer GACGACACCTCTACACATAGCA \\
\hline & & Reverse primer CСТСАТСТTСТССАGССТTСТС \\
\hline \multirow[t]{2}{*}{ IL-6 } & Rat & Forward primer CCGGAGAGGAGACTTCACAG \\
\hline & & Reverse primer CCATAGTGCAGGAGCGTACAGT \\
\hline \multirow[t]{2}{*}{$\| L-1 \beta$} & Rat & Forward primer TGACCCATGTGAGCTGAAAG \\
\hline & & Reverse primer GGGATITGTCGTTGCTTGT \\
\hline \multirow[t]{2}{*}{$T N F-\alpha$} & Rat & Forward primer TGATCCGAGATGTGGAACTG \\
\hline & & Reverse primer CGAGCAGGAATGAGAAGAGG \\
\hline \multirow[t]{2}{*}{ COX-2 } & Rat & Forward primer TСТССААССТСТССТАСТАС \\
\hline & & Reverse primer GCACGTAGTCTTCGATCACT \\
\hline
\end{tabular}




\section{Western Blot Analysis}

The colon samples were homogenized in a radioimmunoprecipitation assay buffer. The lysate proteins were separated using sodium dodecyl sulfate-polyacrylamide gel electrophoresis (SDS-PAGE) and were electro-blotted onto nitrocellulose membranes. The membranes were blocked for $1 \mathrm{~h}$, and then incubated overnight with primary antibodies against p-NF- $\kappa B$ and NF- $\kappa B$ (Santa Cruz Biotechnologies, Inc., Santa Cruz, CA, USA) at $4^{\circ} \mathrm{C}$. The membranes were subsequently washed with Tris-buffered saline/0.1\% (v/v) Tween-20 and incubated for $1 \mathrm{~h}$ with secondary antibodies. After washing the membranes, the protein bands were detected using the FluorChem $\mathrm{E}$ image detection system (ProteinSimple, San Jose, CA, USA). $\beta$-actin was used as a loading control.

\section{Enzyme Linked Immunosorbent Assay (ELISA)}

The protein levels of IL-1 $\beta$ and IL- 6 in rat serum were measured using an ELISA kit (AMEKO Institute of Biotechnology, Shanghai, China) according to the manufacturer's instructions.

\section{Statistical Analysis}

Data are expressed as the mean \pm standard deviation (SD). The statistical differences among study groups were determined by one-way analysis of variance (ANOVA) followed by the least significant difference (LSD). For all comparisons, $P<0.05$ was considered a statistically significant difference. Correlation coefficient (r) was determined using the Pearson's correlation.

\section{RESULTS}

\section{Effect of BZYQD on Constipation in Loperamide Induced Rats}

The body weight did not differ significantly between loperamideinduced group and normal control group (Supplementary Figure 1). The small intestinal transit rate and number of stools were significantly decreased in loperamide induced group than those in normal control group (Figures 3A, B). Treatment with BZYQD markedly increased the small intestinal transit rates and number of stools as compared to those in the loperamide group (Figures 3A, B). As compared with normal control group, the epithelial surface of the rat colon was damaged, mucosa was thinner, gland was reduced, goblet cells were reduced, and the inflammatory cells infiltrated in the lamina propria in the loperamide group; these histological
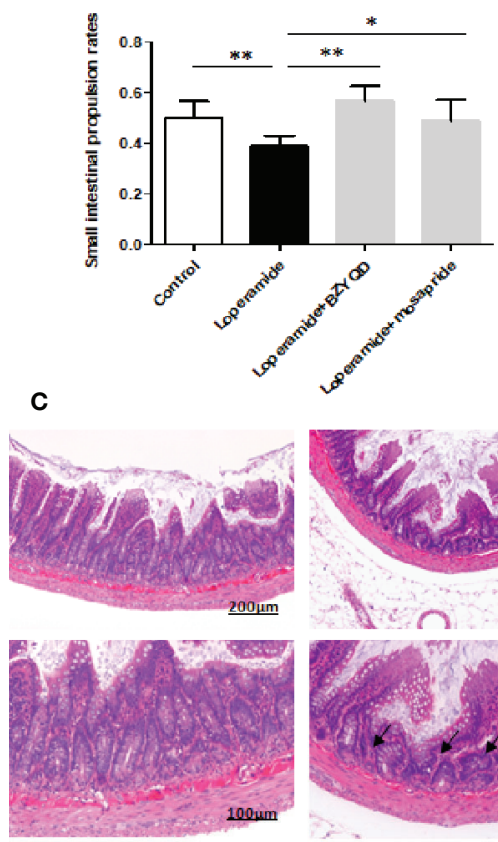

Control
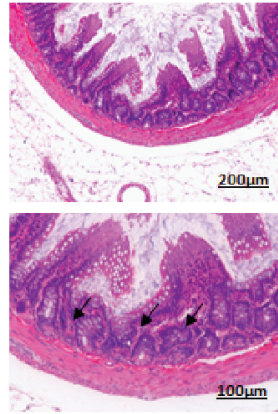

Loperamide

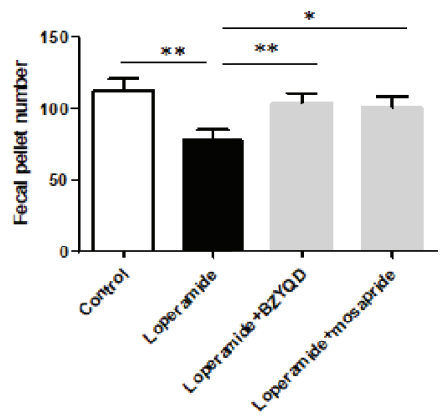

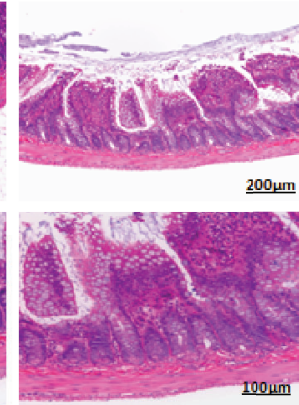

Loperanide+BZYQD
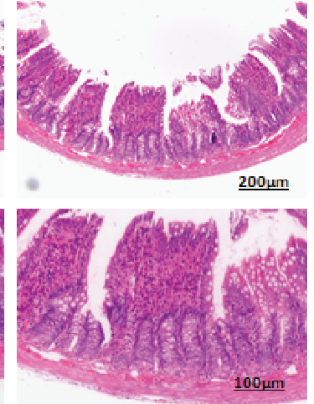

Loperamide+mosapride

FIGURE 3 | Effect of BZYQD intervention on loperamide-induced constipation in rats. (A) Small intestinal transit rates of rats of Control group, Loperamide, Loperamide + BZYQD, and Loperamide + Mosapride groups. (B) Number of stools of rats of Control group, Loperamide, Loperamide + BZYQD, and Loperamide + Mosapride groups. (C) Hematoxylin and eosin (H\&E)-staining for light microscopy analysis of colon sections in rats of the control group, Loperamide group, Loperamide + BZYQD group, Loperamide + Mosapride groups morphology. Arrow marks pointed to that epithelial surface of the rat colon was damaged, mucosa was thinner, gland was reduced, goblet cells were reduced, and the inflammatory cells infiltrated in the lamina propria in the loperamide group. $\mathrm{n}=8$; Original magnification $\times 100$ or $\times 200$; data are represented as mean \pm SD. ${ }^{\#} P<0.05$ versus control group; ${ }^{*} P<0.05$ versus loperamide group, ${ }^{\star \star} P<0.01$ versus $L$ operamide group. 
damages were significantly ameliorated by BZYQD treatment (Figure 3C).

\section{Effect of BZYQD on the Metabolism of Rats with Loperamide-Induced Constipation}

As observed in the PCA plots, the QC samples were clustered closely under both positive and negative monitoring modes, which suggested a stable analysis method (Figures 4A, B). The OPLS-DA results indicated an appreciable separation of the data relating to these three groups (Figures 4C, D). After identification and screening, levels of 29 serum metabolites in the loperamide induced group were significantly different from those in the normal control group, and BZYQD treatment reversed levels of 17 of these metabolites (Table 3). Among these differential metabolites, four were identified using authenticated standards and others were deduced using accurate molecular weights and comparing tandem mass spectrometry fragments with data in metabolomics databases. The levels of metabolites in the three groups are presented as a heatmap (Figure 4E). To further explore the metabolic pathways that BZYQD influenced, these metabolites were imported into
MetaboAnalyst (https://www.metaboanalyst.ca/) to conduct pathway analysis. The related metabolic pathways are listed in Figure 5 and Table 4. The metabolic pathways influenced by BZYQD were arachidonic acid (AA) metabolism, biosynthesis of unsaturated fatty acids, ascorbate and aldarate metabolism, alactose metabolism, and inositol phosphate metabolism. According to the $\mathrm{p}$ value and - $\log$ (p) (Zhang et al., 2015; Wu et al., 2017), arachidonic acid metabolism is one of the main pathways that influenced by BZYQD.

\section{Effect of BZYQD on Inflammatory Response in Rats with Loperamide- Induced Constipation}

As serum metabolomics revealed that the main pathway influenced by BZYQD was AA metabolism, we further investigated the effect of BZYQD on inflammation in loperamide-induced rat colon tissue. As shown in Figures 6A, B, level of serum metabolite $\mathrm{PGE}_{2}$ was significantly increased in Loperamide group compared to that in the Control group, and it decreased by BZYQD treatment. Additionally, expression of cyclooxygenase 2 (COX-2), the key enzyme that produces $\mathrm{PGE}_{2}$ from $\mathrm{AA}$ was also increased in Loperamide group and decreased in BZYQD group. Moreover, the serum levels of

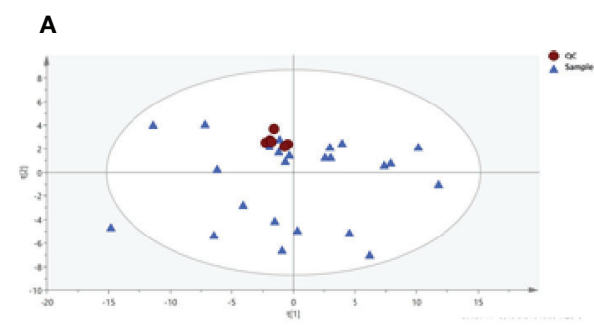

B

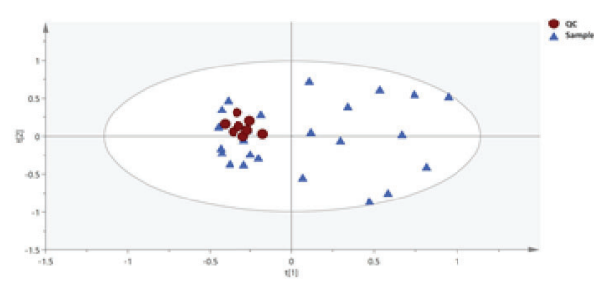

C

D
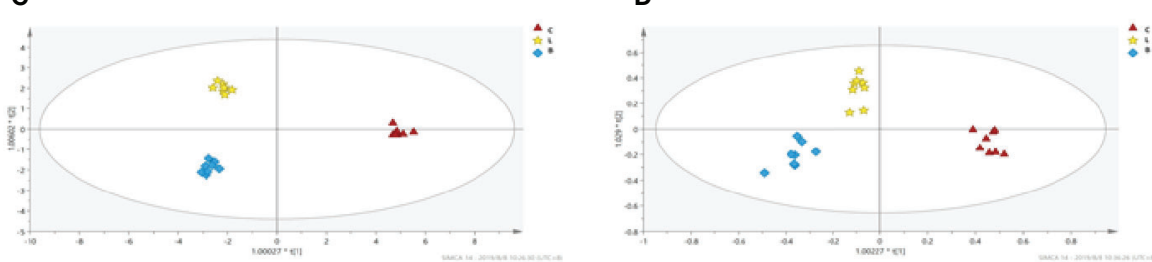

E

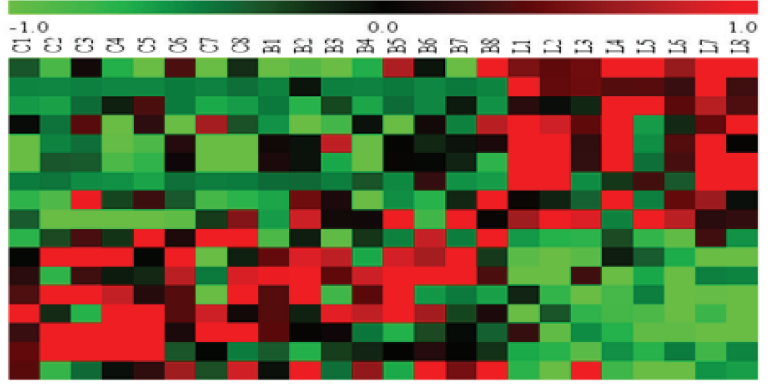

Prostaglandin E2

Chenodeoxycholic acid

1beta-Hydroxycholic acid

Taurou

Indole-3-propionic acid

Ethyl docosnhexnenonte

7-ketodeoxycholic acid

Linoleyl carnitine

Inositol

LysoPE( $20: 1)$

LysoPE( $22: 4)$

Eicosapentanoic acid

LysoPC (14:0)

Arachidonic acic

FIGURE 4 | Effect of BZYQD intervention on serum metabolic profiling in loperamide-treated rats. (A, B) $P C A$ score plot in three groups, $R^{2} X=0.513, Q^{2}=0.41$ in positive model. $R^{2} X=0.567, Q^{2}=0.279$ in negative model. (C, D) OPLS-DA score plot in three groups, $R^{2} X=0.788, R^{2} Y=0.995, Q^{2}=0.515$ in positive model. $R^{2} X=0.544, R^{2} Y=0.918, Q^{2}=0.487$ in negative model. (E) Hierarchical clustering heat map of the differential metabolite levels in control (C), loperamide ( $L$ ), and loperamide + BZYQD groups $(B)(n=8)$. The heat map indicated that the serum levels of nine metabolites (Green color) were decreased, and eight metabolites (Red color) were increased in loperamide + BZYQD group as compared with loperamide group. 
TABLE 3 | Endogenous metabolites identified in the serum of rats included in this study.

\begin{tabular}{|c|c|c|c|c|c|}
\hline VIP & Time & Molecular ion & CompMW & Formula & Metabolites \\
\hline 1.0830 & 8.22 & {$[\mathrm{M}-\mathrm{H}]^{-}$} & 352.47 & $\mathrm{C}_{20} \mathrm{H}_{32} \mathrm{O}_{5}$ & Prostaglandin E2 \\
\hline 1.6241 & 8.16 & {$[\mathrm{M}-\mathrm{H}]^{-}$} & 304.47 & $\mathrm{C}_{20} \mathrm{H}_{32} \mathrm{O}_{2}$ & Arachidonic acid \\
\hline 2.1715 & 6.29 & {$[\mathrm{M}-\mathrm{H}]^{-}$} & 392.57 & $\mathrm{C}_{24} \mathrm{H}_{40} \mathrm{O}_{4}$ & Chenodeoxycholic acid \\
\hline 1.2442 & 6.37 & {$[\mathrm{M}-\mathrm{H}]^{-}$} & 424.28 & $\mathrm{C}_{24} \mathrm{H}_{40} \mathrm{O}_{6}$ & 1beta-Hydroxycholic acid \\
\hline 1.8625 & 5.91 & {$[\mathrm{M}-\mathrm{H}]^{-}$} & 499.70 & $\mathrm{C}_{26} \mathrm{H}_{45} \mathrm{NO}_{6} \mathrm{~S}$ & Tauroursodeoxycholic acid \\
\hline 1.2511 & 8.33 & {$[\mathrm{M}-\mathrm{H}]^{-}$} & 180.16 & $\mathrm{C}_{6} \mathrm{H}_{12} \mathrm{O}_{6}$ & Inositol \\
\hline 1.4063 & 8.89 & {$[\mathrm{M}-\mathrm{H}]^{-}$} & 549.37 & $\mathrm{C}_{28} \mathrm{H}_{56} \mathrm{NO}_{7} \mathrm{P}$ & LysoPC(20:1) \\
\hline 1.1752 & 7.97 & {$[\mathrm{M}+\mathrm{H}]^{+}$} & 571.17 & $\mathrm{C}_{30} \mathrm{H}_{52} \mathrm{NO}_{7} \mathrm{P}$ & LysoPC(22:4) \\
\hline 1.9844 & 5.31 & {$[\mathrm{M}+\mathrm{H}]^{+}$} & 131.17 & $\mathrm{C}_{6} \mathrm{H}_{13} \mathrm{NO}_{2}$ & Leucine \\
\hline 2.0029 & 5.31 & {$[\mathrm{M}+\mathrm{H}]^{+}$} & 189.21 & $\mathrm{C}_{11} \mathrm{H}_{11} \mathrm{NO}_{2}$ & IpA(Indole-3-propionic acid) \\
\hline 1.5352 & 1.11 & {$[\mathrm{M}+\mathrm{H}]^{+}$} & 161.20 & $\mathrm{C}_{7} \mathrm{H}_{15} \mathrm{NO}_{3}$ & Carnitine \\
\hline 1.2700 & 8.70 & {$[\mathrm{M}+\mathrm{H}]^{+}$} & 302.22 & $\mathrm{C}_{20} \mathrm{H}_{30} \mathrm{O}_{2}$ & Eicosapentanoic acid \\
\hline 2.6147 & 6.39 & {$[\mathrm{M}+\mathrm{H}]^{+}$} & 356.27 & $\mathrm{C}_{24} \mathrm{H}_{36} \mathrm{O}_{2}$ & Ethyl docosahexaenoate \\
\hline 1.5642 & 6.14 & {$[\mathrm{M}+\mathrm{H}]^{+}$} & 406.27 & $\mathrm{C}_{24} \mathrm{H}_{38} \mathrm{O}_{5}$ & 7-ketodeoxycholic acid \\
\hline 1.7325 & 8.11 & {$[\mathrm{M}+\mathrm{H}]^{+}$} & 423.33 & $\mathrm{C}_{25} \mathrm{H}_{45} \mathrm{NO}_{4}$ & Linoelaidyl carnitine \\
\hline 1.3189 & 7.58 & {$[\mathrm{M}+\mathrm{H}]^{+}$} & 467.29 & $\mathrm{C}_{22} \mathrm{H}_{46} \mathrm{NO}_{7} \mathrm{P}$ & LysoPC(14:0) \\
\hline 1.7046 & 7.63 & {$[\mathrm{M}+\mathrm{H}]^{+}$} & 541.32 & $\mathrm{C}_{28} \mathrm{H}_{48} \mathrm{NO}_{7} \mathrm{P}$ & LysoPC(20:5) \\
\hline
\end{tabular}

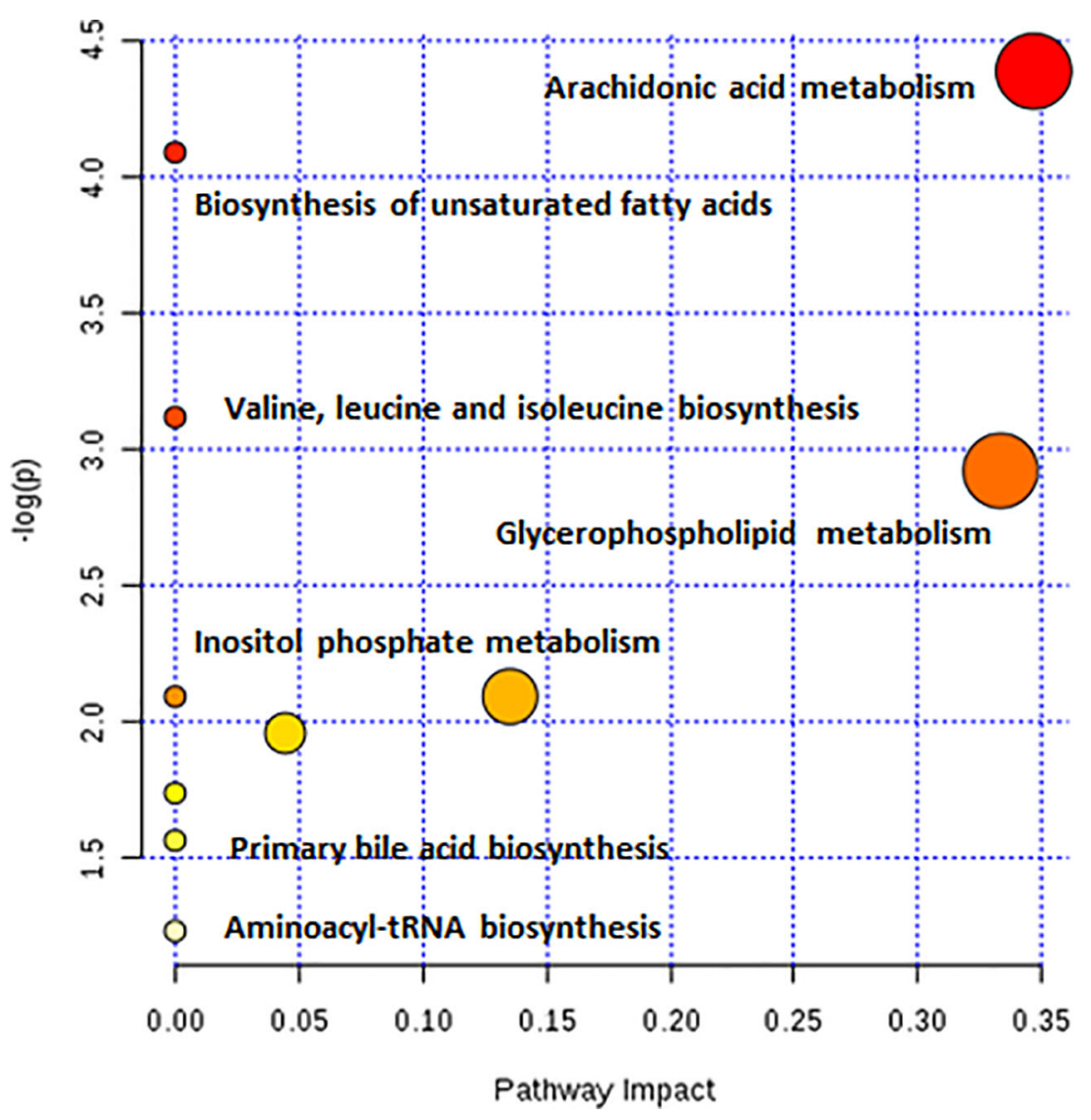

FIGURE 5 | Main pathway analysis associated with metabolites that were influenced by BZYQD.

inflammatory markers, such as IL- $1 \beta$ and TNF- $\alpha$, were significantly increased in Loperamide group as compared with Control group. However, treatment with BZYQD decreased the serum levels of IL$1 \beta$ and TNF- $\alpha$ (Figures 6C, D). Additionally, since differential metabolites, such as $\mathrm{PGE}_{2}$, play an important role in the progression of inflammation, correlation between serum levels of $\mathrm{PGE}_{2}$ and those of IL-1 $\beta$ and TNF- $\alpha$ were tested using the Pearson's correlation. According to the correlation factor ( $r=0.4669$ or $\mathrm{r}=0$. 4675) and $P$-value $(\mathrm{p}=0.0214$ or $\mathrm{p}=0.0213)$, the results indicated serum levels of IL- $1 \beta$ and TNF- $\alpha$ had positive linear correlations 
TABLE 4 | The metabolic pathways that influenced by BZYQD in loperamidetreated rats.

\begin{tabular}{|c|c|c|c|c|c|}
\hline Pathway Name & Total & Hits & $\mathbf{p}$ & $\begin{array}{l}-\log \\
\text { (p) }\end{array}$ & Impact \\
\hline Arachidonic acid metabolism & 36 & 2 & 0.012167 & 4.409 & 0.3468 \\
\hline $\begin{array}{l}\text { Biosynthesis of unsaturated fatty } \\
\text { acids }\end{array}$ & 42 & 2 & 0.016393 & 4.1109 & 0.0000 \\
\hline Ascorbate and aldarate metabolism & 9 & 1 & 0.043713 & 3.1301 & 0.0000 \\
\hline Galactose metabolism & 26 & 1 & 0.12183 & 2.1052 & 0.0000 \\
\hline Inositol phosphate metabolism & 28 & 1 & 0.13065 & 2.0353 & 0.1116 \\
\hline Glycerophospholipid metabolism & 30 & 1 & 0.13939 & 1.9705 & 0.0444 \\
\hline Primary bile acid biosynthesis & 46 & 1 & 0.20667 & 1.5767 & 0.0298 \\
\hline
\end{tabular}

with $\mathrm{PGE}_{2}$ levels (Figures 6E, F). The Pearson's correlation method was descripted as previously reported (Yan et al., 2017; Zheng et al., 2019). Additionally, the mRNA and protein expression of IL-1 $\beta$ and IL-6 in rat colon tissue was also investigated by real-time PCR and immunohistochemistry. As shown in Figure 7, the mRNA and protein expression of IL-1 $\beta$ and IL-6 was significantly increased in Loperamide group, and it decreased by BZYQD treatment (Figure 7). These results suggest that BZYQD treatment decreases loperamide-induced inflammation.

\section{Effect of BZYQD on NF-kB Signaling Pathway in Rats with Loperamide-Induced Constipation}

$\mathrm{PGE}_{2}$ is produced by AA through COX-2, which is regulated by NF- $\kappa B$ signaling pathway. Therefore, the mRNA and protein expression of $\mathrm{p} 65$ in rat colon tissue was further investigated by real-time PCR and western blotting. p65 mRNA expression and p65 and p-p65 protein levels were markedly increased in Loperamide group (Figure 8) than those in the control group. However, treatment with BZYQD significantly decreased p65 mRNA expression and p-p65 protein levels (Figure 8). This result indicated that BZYQD can regulate NF- $\kappa B$ signaling pathway.

\section{Effect of BZYQD on Serum levels of Gastrointestinal Hormone in Rats with Loperamide-Induced Constipation}

The serum levels of gastrointestinal hormone of motilin and gastrin were detected by ELISA. The serum levels of motilin and gastrin were markedly decreased in Loperamide group (Figure 9) than those in the control group. However, treatment with BZYQD significantly increased serum levels of motilin and gastrin (Figure 9). This result indicated that BZYQD can promote gastrointestinal motility.
A
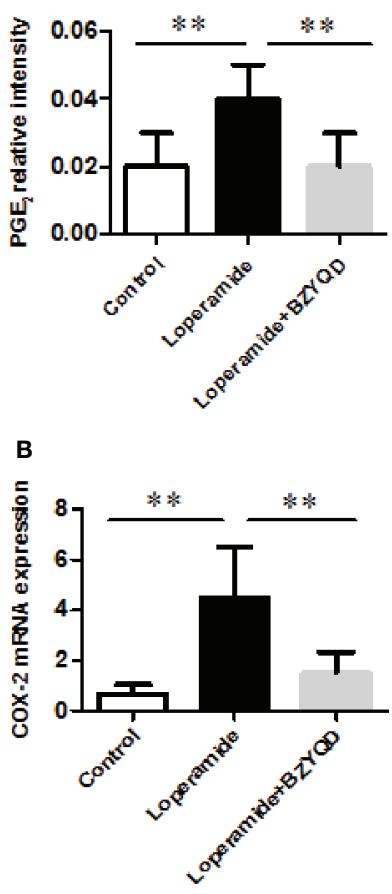

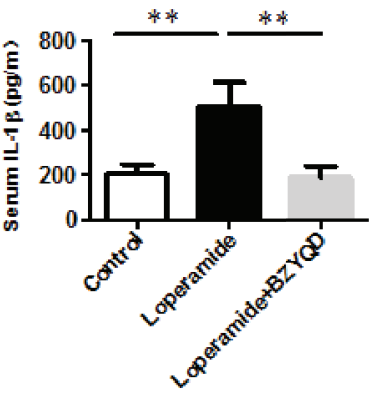

D

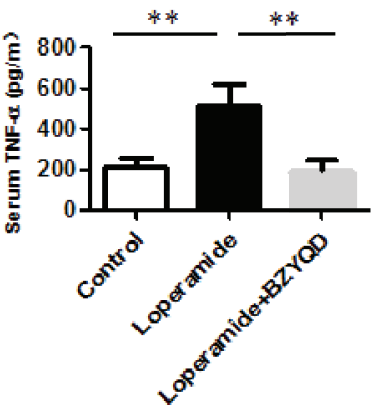

$\mathbf{E}$

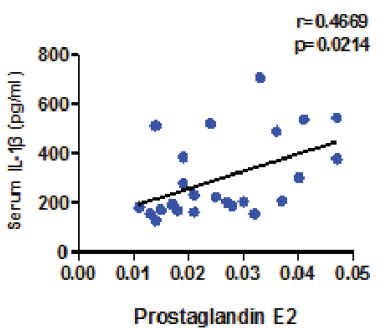

$\mathbf{F}$

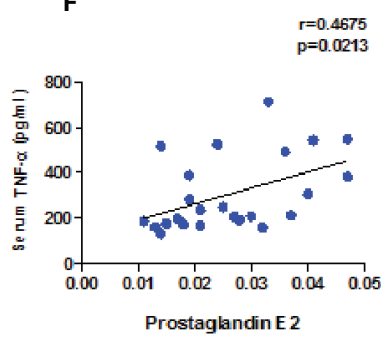

FIGURE 6 | Effect of BZYQD intervention on serum levels of inflammatory factors in loperamide-treated rats. (A) Serum levels of prostaglandin $E_{2}\left(P G E_{2}\right)$ in each group; (B) The mRNA expression of COX-2 in mice colon tissue; (C) Serum levels of IL-6 detected using ELISA in each group; (D) Serum levels of TNF- $\alpha$ detected using ELISA in each group; (E) The correlation between serum levels of IL-6 and serum metabolite PGE 2 ; $(\mathbf{F})$ The correlation between serum levels of TNF- $\alpha$ and serum metabolite $\mathrm{PGE}_{2}$; data are represented as mean $\pm \mathrm{SD}(\mathrm{n}=8) .{ }^{*} P<0.01$ between two groups. Correlation factor $(\mathrm{r})$ and $P$-value were determined using the Pearson's correlation analysis. 

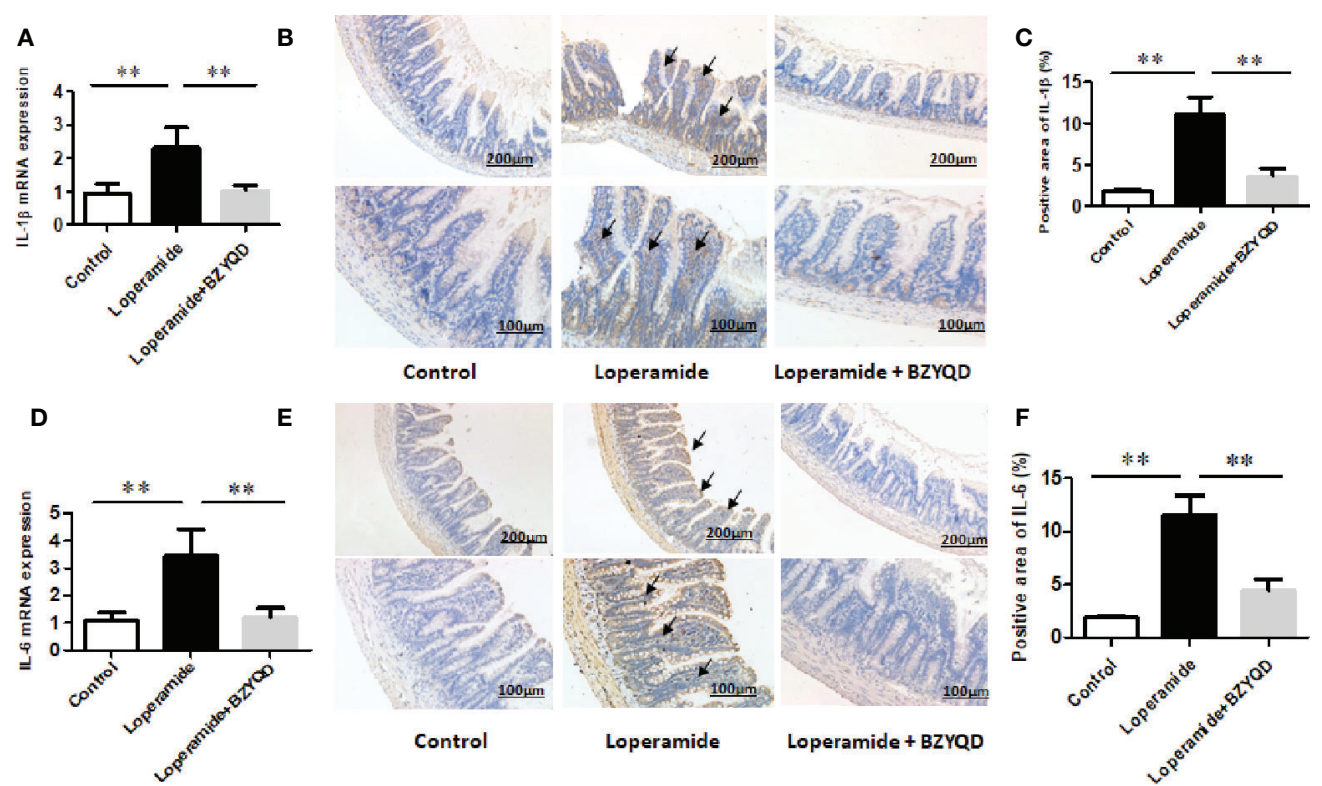

FIGURE 7 | Effect of BZYQD intervention on expression of colon inflammatory factors in loperamide-treated rats. BZYQD decreased the mRNA and protein expression of IL-1 $\beta$ and IL-6: (A) The mRNA expression of IL-1 $\beta$ of colon tissues that detected by real-time PCR; (B) Protein expression of IL-1 $\beta$ of colon tissues that detected using immunohistochemistry; (C) Quantification of protein expression of IL-1 $\beta$ of colon tissues. (D) The mRNA expression of IL-6 of colon tissues that detected by real-time PCR; (E) Protein expression of IL-6 of colon tissues that detected using immunohistochemistry; (F) Quantification of protein expression of 6 of colon tissues. Data are represented as mean \pm SD. Arrow marks pointed to positive area expression. $(n=5)$. ${ }^{\star \star} P<0.01$ between groups.

\section{DISCUSSION}

BZYQD is a classic Chinese herbal formula used to treat gastrointestinal diseases (Gou et al., 2016), but its mechanism of action has not been fully studied. Loperamide is an anti-diarrheal drug commonly used in the clinic, and its mechanism of action mainly involves the inhibition of intestinal peristalsis and intestinal secretion (Zhang et al., 2018). Loperamide is widely used to establish animal constipation models to study the etiology and pathogenesis of constipation (Wu et al., 2010; Han et al., 2017; Zhang et al., 2018; Li et al., 2019). In this study, BZYQD treatment increased the intestinal propulsion rate and improved the colon tissue pathological damage induced by loperamide in a loperamideinduced rat constipation model. Mosapride is a commonly used drug to treat gastrointestinal dysfunction. Mosapride was reported to improve loperamide-induced constipation in rats (Li et al., 2019). In the current study, mosapride was used as a positive drug, and there was no significant difference between BZYQD and mosapride in improving constipation. Overall, our results indicate that BZYQD has protective effects against loperamide-induced constipation.

Metabolomics reveals molecular mechanism pathway by assessing differences in the production of metabolites or endogenous small molecules (Schrimpe-Rutledge et al., 2016). Metabolomics, thus, provides a holistic view of changes in metabolite levels due to drug interventions. TCM comprise a variety of crude herbs that exert a comprehensive therapeutic effect (Wu et al., 2017; Zheng et al., 2019). Metabolomics is very helpful in exploring the mechanisms of action of TCM (Wu et al., 2017; Zheng et al., 2019). In this study, metabolomics was used to analyze the influence of BZYQD on serum metabolites in a loperamide-induced constipation rat model. Our results showed that the levels of 29 metabolites were changed in the loperamide group compared with the control group, and 17 different metabolites were reversed by BZYQD. KEGG pathway analysis revealed that the major pathway that was influenced by BZYQD was the arachidonic acid metabolism, biosynthesis of unsaturated fatty acids, ascorbate and aldarate metabolism, inositol phosphate metabolism. Therefore, the regulation of those metabolic pathways may be key roles in BZYQD against loperamide-induced constipation.

Arachidonic acid metabolism plays an important role in the inflammatory network (Meirer et al., 2014). AA and prostaglandin $\mathrm{E}_{2}\left(\mathrm{PGE}_{2}\right)$ are both important metabolites involved in the AA metabolic pathway. AA is a type $n-6$ polyunsaturated fatty acid highly represented in the composition of phospholipids; moreover, it is the precursor of eicosanoids, such as $\mathrm{PGE}_{2}$, thromboxanes, and leukotrienes, which are long-recognized mediators of inflammation (Akasaka and Ruan, 2016). There have been reports indicating that the increased release of $\mathrm{PGE}_{2}$ can trigger an inflammatory response (Kawahara et al., 2015; Koeberle and Werz, 2015; Tsuge et al., 2019). In the present study, the serum metabolite $\mathrm{PGE}_{2}$ was significantly increased in the loperamide-induced group and decreased upon BZYQD intervention. This result suggests that BZYQD administration may alleviate the inflammatory response induced by loperamide in constipation rats. Histopathological results showed that intervention with BZYQD reduced inflammatory cell infiltration and morphological damage in the colons of rats administered loperamide. Further study showed that BZYQD 
A
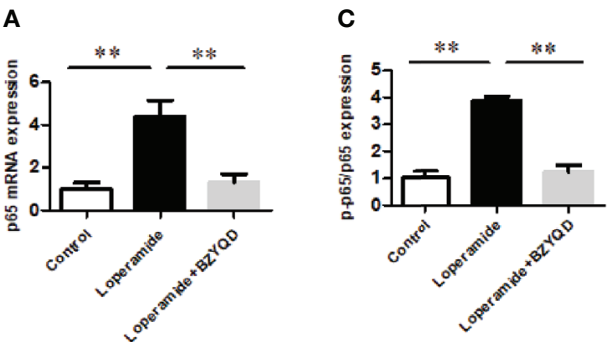

B

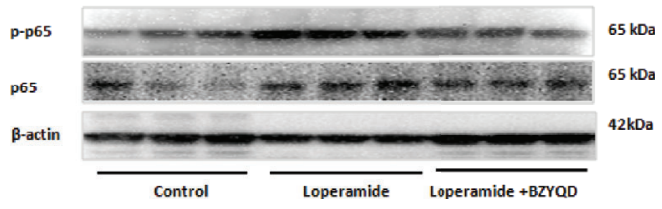

FIGURE 8 | Effect of BZYQD intervention on NF-kB signaling pathway in loperamide-treated rats. (A) The mRNA expression of p65 detected through real-time PCR. (B) The protein expression of p-p65 and p65 detected by western blot. (C) Ratio of protein expression of p-p65 and p65; data are represented as mean $\pm S D ; n=8$ for real-time PCR and $n=3$ for western blot. ${ }^{* \star} P<0.01$ between groups.

intervention reduced the levels of serum inflammatory factors IL-1 $\beta$ and TNF- $\alpha$ and colonic inflammatory factors IL-1 $\beta$ and IL- 6 in constipation rats. Therefore, the above mentioned results also support the results of our metabolomics study. Previous studies have shown that the inflammatory response is closely related to gastrointestinal motility disorders (Ali et al., 2013). Infiltration of inflammatory cells into the digestive tract is a major histological change involved in gastrointestinal motility disorders (Ali et al., 2013). In addition, the release of inflammatory mediators also leads to changes in gastrointestinal motility (Ali et al., 2013). A recent study reported that loperamide-induced rats exhibit a significant colonic inflammatory response, and anti-inflammatory agents help to exert a laxative effect on constipation in these rats (Kim et al., 2019). Thus, consistent with our result, this study showed that inflammation may play an important role in the progression of constipation. Our results also suggested that BZYQD can alleviate the inflammatory response induced by loperamide and ameliorate constipation.

AA is catalyzed by COX-2 to produce the metabolite $\mathrm{PGE}_{2}$ (Tsuge et al., 2019), while COX-2 expression is regulated by the NF- $\mathrm{KB}$ signaling pathway (Zha et al., 2014; Desai et al., 2018). In this study, we found that BZYQD can inhibit $N F-\kappa B$ phosphorylation in the colon of constipation rats, and downregulate the expression of COX-2, thereby reducing the level of $\mathrm{PGE}_{2}$. Therefore, our results suggest that the regulation of the arachidonic acid pathway by BZYQD may occur through the inhibition of the NF- $\kappa \mathrm{B}$ signaling pathway. However, further exploration through future studies is needed. In addition, the release of inflammatory mediators is also known to induce acute inflammatory cell infiltration and promote NF- $\kappa \mathrm{B}$ activity (Kawai and Akira, 2007; Gambhir et al., 2015; Merga et al., 2016). Here, we observed that BZYQD inhibited the activation of the NF- $\kappa \mathrm{B}$ pathway, which may also contribute to its protective effect against loperamide-induced constipation.

There have been reported that inositol phosphate is associated with gastrointestinal hormone motilin and gastrin metabolism (Fang et al., 2010; Goze et al., 2010). In the current study, we have investigated the effect of BZYQD on the serum levels of
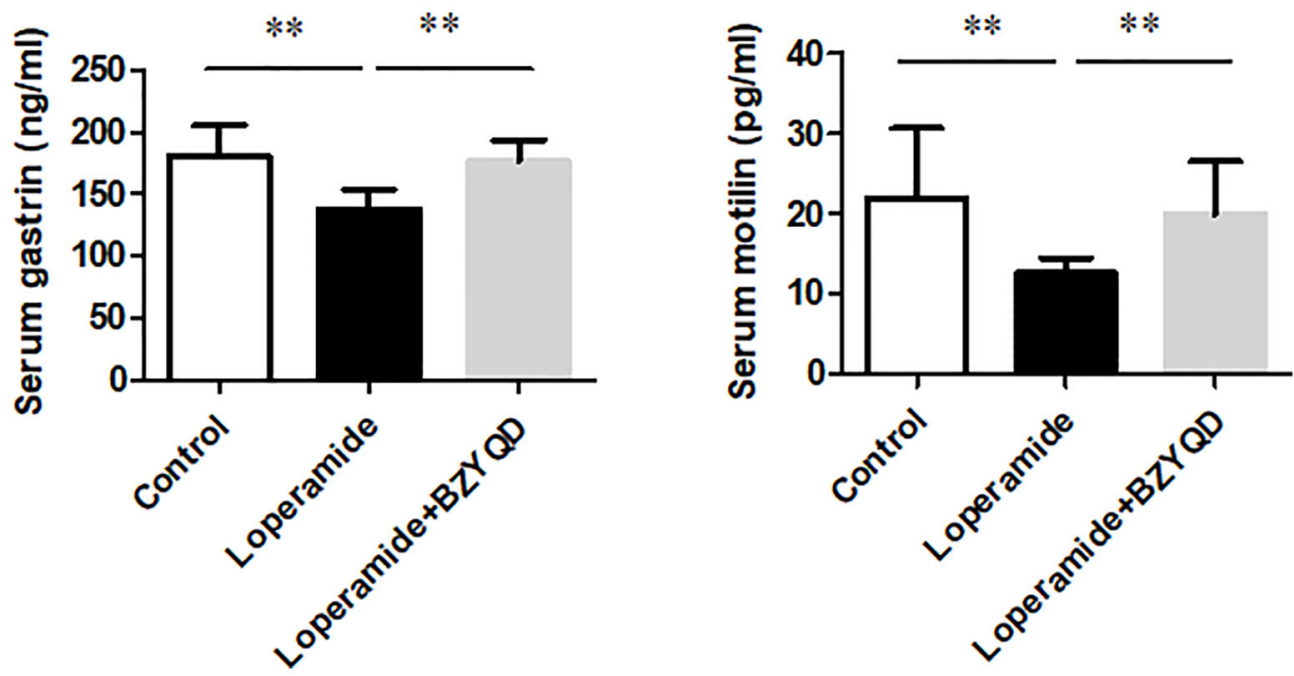

FIGURE 9 | Effect of BZYQD intervention on serum levels of motilin and gastrin in loperamide-treated rats. Data are represented as mean \pm SD; $\mathrm{n}=5 .{ }^{\star \star} P<0.01$ between groups. 
gastrointestinal hormone. Our results indicated that BZYQD increased the serum levels of gastrointestinal hormone motilin and gastrin. Therefore, those results suggested that treatment with BZYQD may promote the gastrointestinal motility of rats with loperamide-induced constipation.

In conclusion, the results of this study demonstrated that BZTQD intervention exerts a protective effect against loperamideinduced constipation, which may be associated with its role in regulation of multiple metabolic pathways.

\section{DATA AVAILABILITY STATEMENT}

All datasets generated for this study are included in the article/ Supplementary Material.

\section{ETHICS STATEMENT}

This study was carried out in accordance with the principles of China Regulations on the Administration of Laboratory Animals, the Decree No. 2 of National Science and Technology Commission of the People's Republic of China. The protocol was

\section{REFERENCES}

Akasaka, H., and Ruan, K. H. (2016). Identification of the two-phase mechanism of arachidonic acid regulating inflammatory prostaglandin E2 biosynthesis by targeting COX-2 and mPGES-1. Arch. Biochem. Biophys. 603, 29-37. doi: 10.1016/j.abb.2016.04.011

Ali, T., Choe, J., Awab, A., Wagener, T. L., and Orr, W. C. (2013). Sleep, immunity and inflammation in gastrointestinal disorders. World J. Gastroenterol. 19, 9231-9239. doi: 10.3748/wjg.v19.i48.9231

Dan, S.L.Y.J.X. (2018). Effects of Bushen Yiqi Decoction on Indexes of Hemotology and Intestinal Sensitivity in Patients with Constipation Predominant Irritable Bowel Syndrome. World Chinses Med. 13, 2196-2199. doi: 10.3969 /j.issn.1673-7202.2018.09.025

Desai, S. J., Prickril, B., and Rasooly, A. (2018). Mechanisms of Phytonutrient Modulation of Cyclooxygenase-2 (COX-2) and Inflammation Related to Cancer. Nutr. Cancer 70, 350-375. doi: 10.1080/01635581.2018.1446091

Fang, P., Dong, L., and Luo, J. Y. (2010). Effects of motilin on intracellular free calcium in cultured smooth muscle cells from the antrum of neonatal rats. Acta Physiol. (Oxf.) 199, 53-61. doi: 10.1111/j.1748-1716.2010.02079.x

Gambhir, S., Vyas, D., Hollis, M., Aekka, A., and Vyas, A. (2015). Nuclear factor kappa B role in inflammation associated gastrointestinal malignancies. World J. Gastroenterol. 21, 3174-3183. doi: 10.3748/wjg.v21.i11.3174

Gou, H., Gu, L. Y., Shang, B. Z., Xiong, Y., and Wang, C. (2016). Protective effect of Bu-Zhong-Yi-Qi decoction, the water extract of Chinese traditional herbal medicine, on 5-fluorouracil-induced intestinal mucositis in mice. Hum. Exp. Toxicol. 35, 1243-1251. doi: 10.1177/0960327115627686

Goze, C., Berge, G., M'kadmi, C., Floquet, N., Gagne, D., Galleyrand, J. C., et al. (2010). Involvement of tryptophan W276 and of two surrounding amino acid residues in the high constitutive activity of the ghrelin receptor GHS-R1a. Eur. J. Pharmacol. 643, 153-161. doi: 10.1016/j.ejphar.2010.06.018

Han, S. H., Park, K., Kim, E. Y., Ahn, S. H., Lee, H. S., and Suh, H. J. (2017). Cactus (Opuntia humifusa) water extract ameliorates loperamide-induced constipation in rats. BMC Complement. Altern. Med. 17, 49. doi: 10.1186/s12906-016-1552-8

He, M., Chen, W., Wang, M., Wu, Y., Zeng, J., Zhang, Z., et al. (2017). Simultaneous determination of multiple bioactive components of Bu-zhongyi-qi-tang in rat tissues by LC-MS/MS: Application to a tissue distribution study. J. Chromatogr. B. Anal. Technol. BioMed. Life Sci. 1044, 177-184. doi: 10.1016/j.jchromb.2017.01.023 approved by the animal ethics committee of the Shanghai University of Traditional Chinese Medicine, China.

\section{AUTHOR CONTRIBUTIONS}

$\mathrm{W}-\mathrm{JJ}$ and Z-KZ performed the experiment. W-JJ completed this manuscript. G-LD designed the experiment. X-PW guided the experiment. S-LC, D-DZ, and W-NY assisted the experiments. $\mathrm{X}-\mathrm{PW}$ and G-LD revised the article.

\section{FUNDING}

The authors are grateful for the financial support from the National Natural Science Foundation of China (81573862).

\section{SUPPLEMENTARY MATERIAL}

The Supplementary Material for this article can be found online at: https://www.frontiersin.org/articles/10.3389/fphar.2020. 00423/full\#supplementary-material

Huang, Y., Tian, Y., Li, G., Li, Y. Y., Yin, X. J., Peng, C., et al. (2013). Discovery of safety biomarkers for realgar in rat urine using UFLC-IT-TOF/MS and H-1 NMR based metabolomics. Anal. Bioanal. Chem. 405, 4811-4822. doi: 10.1007/s00216-013-6842-0

Ji, L. (2006). Fang Ji Xue. Fang Ji Xue 13, 2196-2199. doi: 10.18632/ oncotarget. 21385

Kawahara, K., Hohjoh, H., Inazumi, T., Tsuchiya, S., and Sugimoto, Y. (2015). Prostaglandin E2-induced inflammation: Relevance of prostaglandin E receptors. Biochim. Biophys. Acta 1851, 414-421. doi: 10.1016/j.bbalip.2014.07.008

Kawai, T., and Akira, S. (2007). Signaling to NF-kappaB by Toll-like receptors. Trends Mol. Med. 13, 460-469. doi: 10.1016/j.molmed.2007.09.002

Kim, J. E., Park, J. W., Kang, M. J., Choi, H. J., Bae, S. J., Choi, Y. S., et al. (2019). Anti-Inflammatory Response and Muscarinic Cholinergic Regulation during the Laxative Effect of Asparagus cochinchinensis in Loperamide-Induced Constipation of SD Rats 20. Int. J. Mol. Sci. doi: 10.3390/ijms20040946

Koeberle, A., and Werz, O. (2015). Perspective of microsomal prostaglandin E2 synthase-1 as drug target in inflammation-related disorders. Biochem. Pharmacol. 98, 1-15. doi: 10.1016/j.bcp.2015.06.022

Li, Y. F., Wu, J. S., Li, Y. Y., Dai, Y., Zheng, M., Zeng, J. K., et al. (2017). Chicken bile powder protects against alpha-naphthylisothiocyanate-induced cholestatic liver injury in mice. Oncotarget 8, 97137-97152.

Li, X., Liu, Y., Guan, W., Xia, Y., Zhou, Y., Yang, B., et al. (2019). Physicochemical properties and laxative effects of polysaccharides from Anemarrhena asphodeloides Bge. in loperamide-induced rats. J. Ethnopharmacol. 240, 111961. doi: 10.1016/j.jep.2019.111961

Mearin, F., Lacy, B. E., Chang, L., Chey, W. D., Lembo, A. J., Simren, M., et al. (2016). Bowel Disorders. Gastroenterology. 16, 222-225. doi: 10.1053/j.gastro.2016.02.031

Meirer, K., Steinhilber, D., and Proschak, E. (2014). Inhibitors of the arachidonic acid cascade: interfering with multiple pathways. Basic Clin. Pharmacol. Toxicol. 114, 83-91. doi: 10.1111/bcpt.12134

Merga, Y. J., O'hara, A., Burkitt, M. D., Duckworth, C. A., Probert, C. S., Campbell, B. J., et al. (2016). Importance of the alternative NF-kappaB activation pathway in inflammation-associated gastrointestinal carcinogenesis. Am. J. Physiol. Gastrointest. Liver Physiol. 310, G1081-G1090. doi: 10.1152/ajpgi.00026.2016

Schrimpe-Rutledge, A. C., Codreanu, S. G., Sherrod, S. D., and Mclean, J. A. (2016). Untargeted Metabolomics Strategies-Challenges and Emerging Directions. J. Am. Soc. Mass Spectrom. 27, 1897-1905. doi: 10.1007/s13361016-1469-y 
Suares, N. C., and Ford, A. C. (2011). Prevalence of, and risk factors for, chronic idiopathic constipation in the community: systematic review and meta-analysis. Am. J. Gastroenterol. 106, 1582-1591; quiz 1581, 1592. doi: 10.1038/ajg.2011.164 Sun Feng-Wei, Y. Q.-Y. (2016). Modified Buzhong Yiqi Decoction Treating 49 Cases of Senile Constipation of Spleen Deficiency Syndrome. Liao Ning J. Tradit. Chin. Med. 43, 554-556. doi: 1013192 / jissn1000-1719201603040

Tsuge, K., Inazumi, T., Shimamoto, A., and Sugimoto, Y. (2019). Molecular mechanisms underlying prostaglandin E2-exacerbated inflammation and immune diseases. Int. Immunol. doi: 10.1093/intimm/dxz021

Wang, N. J., Wang, J. H., Fu, D. Z., and Shao, T. Y. (1991). Study on pharmacological effects on Buzhongyiqi decocotion -the effects and mechanism of BZYQD on preventing or treating experimental gastric ulcer. Pharmacol. Clinics Chin. Mater. Med., 1-5. doi: 10.13412/j.cnki.zyyl.1991.05.001

Wu, D., Wang, X., Zhou, J., Yuan, J., Cui, B., An, R., et al. (2010). Traditional Chinese formula, lubricating gut pill, improves loperamide-induced rat constipation involved in enhance of $\mathrm{Cl}$ - secretion across distal colonic epithelium. J. Ethnopharmacol. 130, 347-353. doi: 10.1016/j.jep.2010.05.018

Wu, J. S., Li, Y. F., Li, Y. Y., Dai, Y., Li, W. K., Zheng, M., et al. (2017). Huangqi Decoction Alleviates Alpha-Naphthylisothiocyanate Induced Intrahepatic Cholestasis by Reversing Disordered Bile Acid and Glutathione Homeostasis in Mice. Front. Pharmacol. 8, 938. doi: 10.3389/fphar.2017.00938

Yan, J., Xie, G., Liang, C., Hu, Y., Zhao, A., Huang, F., et al. (2017). Herbal medicine Yinchenhaotang protects against alpha-naphthylisothiocyanateinduced cholestasis in rats. Scientific Report. 7, 4211. doi: 10.1038/s41598017-04536-5

Zha, L., Chen, J., Sun, S., Mao, L., Chu, X., Deng, H., et al. (2014). Soyasaponins can blunt inflammation by inhibiting the reactive oxygen species-mediated activation of PI3K/Akt/NF-kB pathway. PloS One 9, e107655. doi: 10.1371/ journal.pone.0107655

Zhang, Z. H., Wei, F., Vaziri, N. D., Cheng, X. L., Bai, X., Lin, R. C., et al. (2015). Metabolomics insights into chronic kidney disease and modulatory effect of rhubarb against tubulointerstitial fibrosis. Sci. Rep. 5, 14472. doi: 10.1038/ srep 14472

Zhang, Y., Ge, T., Xiang, P., Mao, H., Tang, S., Li, A., et al. (2018). Therapeutic effect of protease-activated receptor 2 agonist SLIGRL-NH2 on loperamideinduced Sprague-Dawley rat constipation model and the related mechanism. Drug Des. Devel Ther. 12, 2403-2411. doi: 10.2147/DDDT.S160628

Zhang, X., Wang, Y., Li, X., Dai, Y., Wang, Q., Wang, G., et al. (2019). Treatment Mechanism of Gardeniae Fructus and Its Carbonized Product Against Ethanol-Induced Gastric Lesions in Rats. Front. Pharmacol. 10, 750. doi: 10.3389/fphar.2019.00750

Zhang, E. A. (2016). Clinical observation on functional constipation (qi deficiency type) with Buzhong Yiqi decoction. J. Shanxi Coll. Tradit. Chin. Med. 17, 4243. doi: 10.13192/j.issn.1000-1719.2016.03.040

Zheng, M., Li, Y. Y., Wang, G. F., Jin, J. Y., Wang, Y. H., Wang, T. M., et al. (2019). Protective effect of cultured bear bile powder against dimethylnitrosamineinduced hepatic fibrosis in rats. BioMed. Pharmacother. 112, 108701. doi: 10.1016/j.biopha.2019.108701

Conflict of Interest: Author DZ was employed by company Gen Chim Testing Co., Ltd.

The remaining authors declare that the research was conducted in the absence of any commercial or financial relationships that could be construed as a potential conflict of interest.

Copyright (c) $2020 \mathrm{Ju}$, Zhao, Chen, Zhou, Yang, Wen and Du. This is an open-access article distributed under the terms of the Creative Commons Attribution License (CC $B Y)$. The use, distribution or reproduction in other forums is permitted, provided the original author(s) and the copyright owner(s) are credited and that the original publication in this journal is cited, in accordance with accepted academic practice. No use, distribution or reproduction is permitted which does not comply with these terms. 